\title{
Primary Involvement of Allografted liver in Post-Transplant Lymphoprolif- erative Disorders, Report of Two Pediatric Cases and Review of the Literature
}

\author{
Bita Geramizadeh ${ }^{1^{*}}$, Sama Nikeghbalian ${ }^{2}$, Seyed Mohsen Dehghani ${ }^{3}$, Ali Bahador ${ }^{4}$, Hesh- \\ matollah Salahi ${ }^{5}$, Seyedali Malekhosseini ${ }^{5}$ \\ ${ }^{1}$ Department of Pathology, Shiraz University of Medical Sciences, Shiraz, Iran \\ ${ }^{2}$ Department of Hepatobiliary Surgery, Transplant Research Center, Shiraz University of Medical Sciences, Shiraz, Iran \\ ${ }^{3}$ Department of Pediatrics, Shiraz University of Medical Sciences, Shiraz, IR Iran \\ ${ }^{4}$ Department of Pediatric Surgery, Transplant Research Center, Shiraz University of Medical Sciences, Shiraz, Iran \\ ${ }^{5}$ Department of Surgery, Transplant Research Center, Shiraz University of Medical Sciences, Shiraz, Iran \\ * Corresponding author: Bita Geramizadeh, Department of Pathology, Shiraz University of Medical Sciences, Shiraz, Iran. Tel.: +98-711-6474331, Fax: E-mail: \\ geramib@sums.ac.ir
}

\begin{abstract}
A B S T R A C T
Post-transplant lymphoproliferative disorder is a lymphocyte proliferating disease, usually of B cell origin, and rarely of T cell. Involvement of liver itself in liver transplant recipients as the primary organ is not common. Herein we report our experience in two patients who primarily presented in the allografted liver, both of whom were promptly diagnosed after liver biopsy and treated successfully. Now after a few months; both of the patients are alive with normal liver function tests and negative imaging studies.
\end{abstract}

Keywords: Liver; Lymphoproliferative Disorders

\section{Introduction}

Post-Transplant lymphoproliferative disorder (PTLD) consists of a heterogeneous group of lymphoproliferative disorders which occurs in.1-4.7\% of orthotopic liver transplantations (OLT) and its incidence depends on the age of patient and immunosuppressive therapy used (1). PTLD in OLT patients typically presents as a systemic illness and it rarely presents with involvement of hepatic allograft (2). Among more than 1000 OLT patients in our center we had two patients presented with PTLD in the allografted liver. Herein we report our experience with these two liver transplant patients who had biopsy proven liver involvement.

\section{Case Presentation}

\subsection{Case 1}

A 3-year-old boy underwent OLT for cirrhosis secondary to tyrosinemia (HBS and HCV negative). His immediate post-transplant course was unremarkable. After 6 months he developed constipation, vomiting and fever ( $\mathrm{T}>380 \mathrm{C})$. At that time he was receiving Tacrolimus, mycophenolate mofetil and prednisolone. His laboratory findings are summarized in Table 1.

Liver ultrasonography showed a hypoechoic lesion measuring $14 \times 16 \mathrm{~mm}$ in medial segment of left lobe. Liver biopsy was performed which showed severe infiltration of highly atypical mononuclear cells in the portal tracts with parenchymal involvement ( Figure 1).

\footnotetext{
-Article type: Case Report; Received: 30 Mar 2011, Revised: 21 Aug 2011, Accepted: 19 Sept 2011; DOI: 10.5812/ircmj.1134

Implication for health policy/practice/research/medical education:

In this study we report our experience with these two liver transplant patients who had biopsy proven liver involvement.

Please cite this paper as:

Geramizadeh B, Nikeghbalian S, Dehghani SM, Bahador A, Salahi H, Malekhosseini SA. Primary Involvement of allografted Liver in Post-Transplant Lymphoproliferative Disorders, Report of Two Pediatric. Iran Red Cres Med J.2012;14(11):724-6. DOI:10.5812/ircmj.1134

Copyright ( 2012, Iranian Red Crescent Medical Journal; Published by Kowsar Corp.

This is an Open Access article distributed under the terms of the Creative Commons Attribution License (http://creativecommons.org/licenses/by/3.0), which permits unrestricted use, distribution, and reproduction in any medium, provided the original work is properly cited.
} 
Table 1. Laboratory findings in 2 patients with PTLD presentation in the allografted liver

\begin{tabular}{lll}
\hline & Case No-1 & Case No-2 \\
\hline ALT $^{\text {a }}$ & $75 \mathrm{IU} / \mathrm{L}$ & $69 \mathrm{IU} / \mathrm{L}$ \\
AST $^{\text {a }}$ & $34 \mathrm{IU} / \mathrm{L}$ & $266 \mathrm{IU} / \mathrm{L}$ \\
Alk-P $^{\mathrm{a}}$ & $371 \mathrm{IU} / \mathrm{L}$ & $200 \mathrm{IU} / \mathrm{L}$ \\
LDH $^{\mathrm{a}}$ & $530 \mathrm{IU} / \mathrm{L}$ & $450 \mathrm{IU} / \mathrm{L}$ \\
CRP $^{\mathrm{a}}$ & positive & positive \\
EBV-VCA $^{\mathrm{a}}$ & positive & positive \\
WBC $^{\mathrm{a}}$ & $3200 / \mathrm{ml}$ & $3700 / \mathrm{ml}$ \\
Hemoglobin & $8.2 \mathrm{gr} / \mathrm{l}$ & $7.2 \mathrm{gr} / \mathrm{l}$ \\
\hline Platelet & $100000 / \mathrm{ml}$ & $120000 / \mathrm{ml}$ \\
\hline
\end{tabular}

a ALT: Alanine aminotransferase (normal<41IU/L), AST: Aspartate aminotransferase (normal<37IU/L), Alk-P: alkaline phosphatase $<1200$ IU/L), LDH: lactate dehydrogenase (normal<500 IU/L), CRP: C-reactive protein, EBV-VCA: Epstein Barr-virus viral capsid antibody, WBC: White blood cell count

All of these cells were reactive with B cell markers such as CD 20 and CD 79 ( Figure 2 ). LMP-1 antigen of EBV was positive in some of the above mentioned atypical cells. EBV-PCR was also positive in the liver tissue.

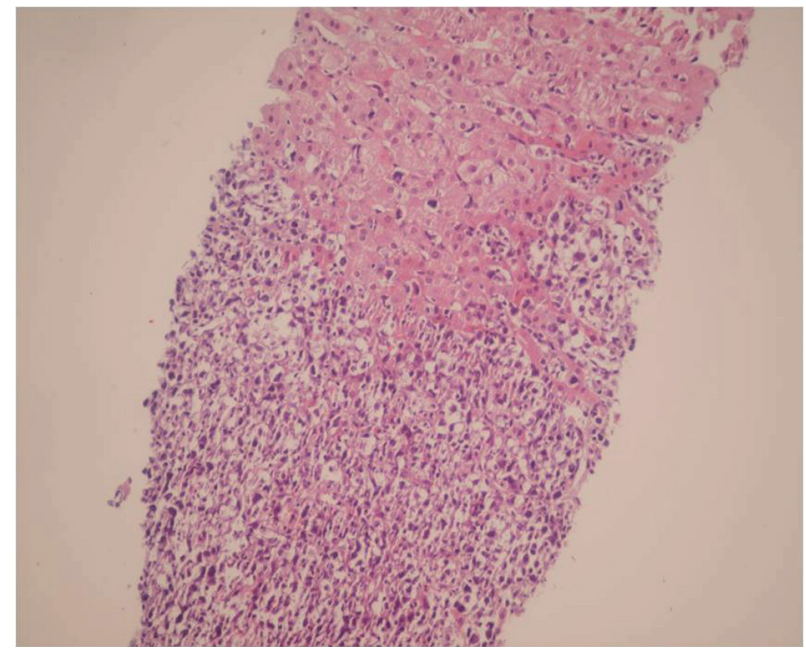

Figure 1. Liver Biopsy Shows Infiltration of Lymphoma Cells in Two Cases. (H\&E X 250)

With the diagnosis of monomorphic PTLD (B cell type), doses of immunosuppressive drugs were reduced, but he remained febrile and gradually became severely pancytopenic. Bone marrow aspiration and biopsy were performed which showed lymphomatous involvement. Standard chemotherapy of CHOP regimen (cyclophosphamide, adriamycin, vincristine, and prednisolone) plus Retuximub was started for him .Now after 9 months, he is doing well and in an acceptable condition. There is no evidence of tumor recurrence in both imaging studies and laboratory tests.

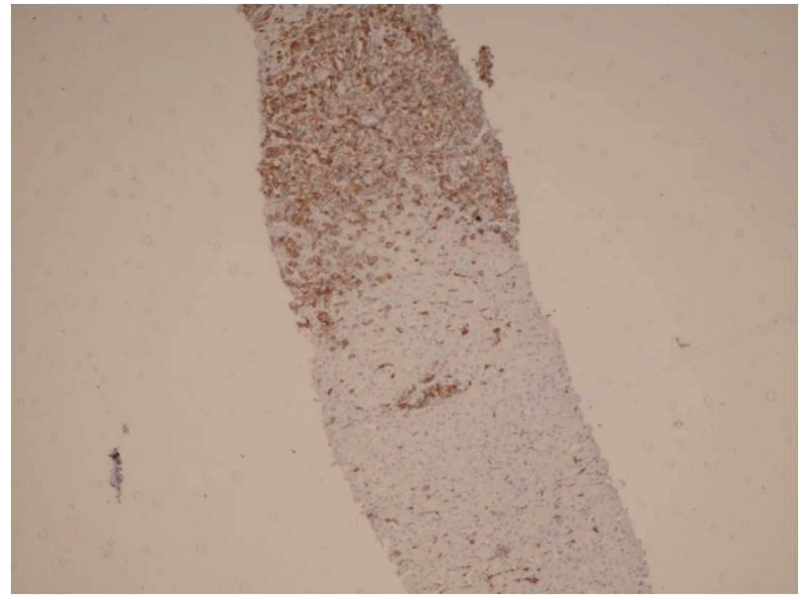

Figure 2. Immunohistochemistry Shows Reactive Lymphoma Cells with CD 20

\subsection{Case 2}

A 16-month-old male underwent OLT for Crigler-Najjar syndrome (HBS and HCV negative). He had an uncomplicated post-transplant period on Tacrolimus, mycophenolate mofetil and prednisolone. After 6 months he developed fever and abnormal liver function tests. His laboratory data are shown in table-1. Imaging studies didn't show any focal lesion. Liver biopsy was done which showed portal infiltration of atypical lymphoid cells with irregular nuclear border (Fig-1b) which were positive with $\mathrm{CD} 20$ and negative with CD3, and CD30.Although LMP-1 by immunohistochemistry was negative but PCR for EBV was positive in the liver tissue. The immunosuppressive drugs were reduced, but he remained febrile and after about 2 weeks he developed cervical lymphadenopathy, lymph node biopsy showed diffuse large B cell lymphoma, so CHOP regimen plus Retuximab was started. After a couple of weeks, the enlarged lymph nodes were disappeared and now after 6 months, he is alive and symptom-free. Imaging studies including ultrasonography failed to show significant finding, and imaging of the transplanted liver is normal.

\section{Discussion}

PTLD is a potential complication of transplanted patients with varying incidence based on the transplanted organ and immunosuppressive regimen (3). PTLD in OLT patients typically presents as a systemic illness with rare presentation in the hepatic graft (4). PTLD in the allografted liver as a part of systemic disease or alone has been reported from 0 to $8 \%$ in pediatric group from different centers (5-7). Therefore, it seems that liver localized PTLD as the first presentation in pediatric age group is rare (2). There are rare reports concerning the differences between PTLD presenting in the liver allograft and systemic PTLD. Capello et al (8) in their report have described this 
issue and concluded that liver allograft PTLDs are of donor origin, mostly B cell type, early onset and pathogenetically related to EBV infection as our two patients. In an OLT patient, PTLD with liver involvement presents with variable symptoms such as fever, chills, nausea and jaundice (9). Both of our patients presented with fever and abnormal liver function tests and liver biopsy was performed to exclude a rejection episode and to diagnose the source of fever. EBV plays a special role in the pathogenesis of lymphoproliferative disorders that develop in the grafted liver $(9,10)$. EBV has the ability to stimulate $B$ cells to proliferate and transform. After primary infection, EBV persists in the B cells and causes a latent infection. In the process of latency during reactivation after immunosuppression, it can cause lymphoproliferative diseases such as PTLD (11). In both of our cases association with the EBV was definite, because the EBV-PCR in the liver tissue was positive. Some authors believe that the type of immunosuppressive regimen play a crucial role in the pathogenesis of PTLD specially OKT3, antilymphocyte globulin (ALG) and antithymocyte globulin (ATG), but others found no significant association except for treatment with antithymocyte globulin $(1,12)$.

The first step of the treatment in PTLD is decreasing immunosuppression (11). In none of our patients, this was curative and both of them required chemotherapeutic regimen including Retuximab and standard protocol. After that a clear regression of liver lesions was noticed and liver function tests became normal. According to our experience, the liver localization of PTLD does not change the management of PTLD, i.e. chemotherapy and decreasing immunosuppression can induce subsequent remission without graft rejection. This finding has also been reported in previous studies $(12,13)$. Our experience in these two patients insists on the value of the early diagnosis of PTLD by performing liver biopsy, so clinicians taking care of the OLT patients should consider PTLD with liver involvement or liver localized PTLD as the possible cause of abnormal liver function test and fever $(14,15)$.

\section{Acknowledgements}

None declared.

\section{Financial Disclosure}

None declared.

\section{Funding/Support}

None declared.

\section{References}

1. Chan DT, Boet R, Poon WS, Yap F, Chan YL. Spinal shock in spontaneous cervical spinal epidural haematoma Acta Neurochir(Wien). 2004;146(10):1161-2.

2. Chen CJ, Hsu WC. Imaging findings of spontaneous spinal epidural hematoma. J Formos Med Assoc. 1997;96(4):283-7.

3. Liao CC, Lee ST, Hsu WC, Chen LR, Lui TN, Lee SC. Experience in the surgical management of spontaneous spinal epidural hematoma. J Neurosurg. 2004;100(1 Suppl Spine):38-45.

4. Alexiadou-Rudolf C, Ernestus RI, Nanassis K, Lanfermann $\mathrm{H}$, Klug N. Acute nontraumatic spinal epidural hematomas, An important differential diagnosis in spinal emergencies. Spine. 1998;23(16):1810-3.

5. Groen RJ. Non-operative treatment of spontaneous spinal epidural hematomas: a review of the literature and a comparison with operative cases. Acta Neurochir(Wien). 2004;146(2):103-10.

6. Guzel A, Simsek O, Karasalihoglu S, Kucukugurluoglu Y, Acunas B, Tosun A, et al. Spontaneous spinal epidural hematoma after seizure. Clin Pediatr(Phila). 2007;46(3):263-5.

7. Park DH, Cho TH, Lee JB, Park JY, Park YK, Chung YG, et al. Rapid spontaneous remission of a spontaneous spinal chronic subdural hematoma in a child. Neurol Med Chir (Tokyo). 2008;48(5):2314 .

8. Bisson EF, Dumont T, Tranmer B, . Spontaneous spinal epidural hematoma in a child with hemophilia B. Can J Neurol Sci. 2007;34(4):488-90.

9. Hsieh CT, Chang CF, Lin EY, Tsai TH, Chiang YH, Ju DT. Spontaneous spinal epidural hematomas of cervical spine: report of 4 cases and literature review. Am J Emerg Med. 2006;24(6):736-40.

10. Solheim O, Jorgensen JV, Nygaard OP. Lumbar epidural hematoma after chiropractic manipulation for lower-back pain. Neurosurgery. 2007;61(1):E170-1.

11. Patel H, Boaz JC, Phillips JP, Garg BP. Spontaneous spinal epidural hematoma in children. Pediatr Neurol.1998;19(4):302-7.

12. Shin JJ, Kuh SU, Cho YE. Surgical management of spontaneous spinal epidural hematoma Eur Spine J. 2006;15(6):998-1004.

13. Yu HP, Fan SW, Yang HL, Tang TS, Zhou F, Zhao X. Early diagnosis and treatment of acute or subacute spinal epidural hematoma. Chin Med J (Engl). 2007;120(15):1303-8.

14. Poonai N, Rieder MJ, Ranger A, . Spontaneous spinal epidural hematoma in an 11-month-old girl. Pediatr Neurosurg. 2007;43(2):432.

15. Park J, Lee JB, Park JY, Lim DJ, Kim SD, Chung YK. Spinal cord infarction after decompressive laminectomy for spontaneous spinal epidural hematoma. Neurol Med Chir(Tokyo).2007;47(7):325-7. 